\title{
Analisis Penanganan Daerah Rawan Kecelakaan Kabupaten Karanganyar
}

\author{
Yogi Oktopianto $^{* 1}$, Tri Prasetyo $^{2}$, Yusuf Maulana Arief ${ }^{3}$ \\ 1,2,3 Program Studi Manajemen Keselamatan Transportasi Jalan, \\ Politeknik Keselamatan Transportasi Jalan, Tegal \\ e-mail: *yogi.oktopianto@pktj.ac.id
}

Received 06 July 2021; Reviewed 15 July 2021; Accepted 09 August 2021

Journal Homepage: http://jurnal.borneo.ac.id/index.php/borneoengineering

\begin{abstract}
The lowest accident fatality index in Karanganyar Regency occurred in 2016 at 3\% and continues to increase to $5 \%$ in 2020. This of course must be an important, and efforts need to be made to change the increase in fatalities each year to a decrease. The study was conducted to analyze the handling of accident-prone areas (Black Site) in Karanganyar Regency. The methods used in this study include the EAN and Frequency methods to analyze the determination of accident-prone areas. Cumulative Summary method to analyze accident-prone points (black spot) and traffic analysis on a micro-scale in accident-prone points (black spot). The recommendations proposed for handling accident-prone areas in Karanganyar Regency include the procurement of speed limit signs, intersection warning signs, turnaround signs, black spot warning signs, caution signs, procurement of APILL (Traffic Signaling Equipment) with yellow color, repair of markings and socialization to the community.
\end{abstract}

Keywords: Black Site; Black spot; Accident-Prone Areas; EAN; Z-Score

\begin{abstract}
Abstrak
Indeks fatalitas kejadian kecelakaan di Kabupaten Karanganyar paling rendah terjadi pada tahun 2016 yaitu sebesar 3\% dan terus mengalami kenaikan hingga sebesar 5\% pada tahun 2020. Hal ini tentunya harus menjadi catatan penting, serta perlu adanya upaya untuk mengubah peningkatan fatalitas tiap tahunnya menjadi menurun. Penelitian dilakukan untuk menganalisis penanganan daerah rawan kecelakaan Kabupaten Karanganyar. Metode yang digunakan dalam penelitian ini meliputi metode EAN dan Frekuensi untuk menganalisis penentuan daerah rawan kecelakaan. Metode Cumulative Summary untuk menganalisis titik rawan kecelakaan, and analisis lalu lintas dalam skala mikro pada lokasi atau daerah rawan kecelakaan. Rekomendasi yang di usulkan penanganan daerah rawan kecelakaan Kabupaten Karanganyar antara lain Pengadaan rambu batas kecepatan, rambu peringatan persimpangan, rambu petunjuk putar balik, rambu peringatan DRK, rambu hati-hati, pengadaan APILL dengan satu warna (kuning), perbaikan marka dan sosialisasi terhadap masyarakat.
\end{abstract}

Kata kunci: Daerah Rawan Kecelakaan; Lokasi Rawan Kecelakaan; Daerah Rawan Kecelakaan; EAN; Z-Score

\section{Pendahuluan}

Berdasarkan posisi geografis, Kabupaten Karanganyar berada pada batas wilayah sebelah barat Kota Surakarta dan Kabupaten Boyolali, Sebelah Timur Provinsi Jawa Timur dan Kabupaten Magetan, sebelah utara Kabupaten Sragen, dan sebelah selatan Kabupaten Wonogiri dan Kabupaten Sukoharjo. Dengan kondisi tersebut Kabupaten Karanganyar merupakan salah satu kota 
dengan mobilitas yang tinggi. Dari data Kepolisian Kabupaten Karanganyar kejadian kecelakaan dari tahun 2016 sampai 2020 sebanyak 5343 kejadian (Kepolisian Kabupaten Karanganyar, 2020), dengan tingginya mobilitas yang semakin meningkat dari tahun ke tahun tentunya akan menjadi sebuah permasalahan transportasi jalan di masa depan jika tidak dilakukan penanganan yang tepat. Kecelakaan lalu lintas jalan raya disebabkan oleh beberapa faktor yang berhubungan dengan sistem lalu lintas: pengguna jalan raya, lingkungan jalan raya dan kendaraan. Menurut penelitian penelitian yang dilakukan di kota Lubuklinggau dengan hasil menyebutkan penyebab kecelakaan lalu lintas ialah kelalaian pengendara kendaraan (human error) dan kurang tersedianya infrastruktur yang memadai pada ruas jalan yang rawan kecelakaan (Carina, 2014). Penyebab utama kecelakaan lalu lintas adalah perilaku mengemudi yang dipengaruhi oleh kondisi lalu lintas dan parameter infrastrukturlainnya (Gregoriades \& Mouskos, 2013).

Faktor penyebab kecelakaan lain yang terjadi di kabupaten Tapin akibat kelalaian masing-masing pengendara dimana mereka terlalu cepat berkendara, saling mendahului kendaraan yang berada di depan dengan mengambil lajur kanan sehingga tabrakan terjadi dengan rekomendasi penanganan untuk meminimalisir kecelakaan lalu lintas paling dominan berupa pemasangan fasilitas jalan dan penyuluhan keselamatan berkendara (Lestari, 2018). Karakteristik daerah rawan kecelakaan (black site) dan titik rawan kecelakaan (black spot) lalu lintas dipengaruhi oleh penggunaan lahan, geometrik jalan, volume lalu lintas, kapasitas jalan, dan rambu lalu lintas (Isa Al Qurni, 2016). Kecelakaan lalu lintas disebabkan oleh kesalahan manusia 66,67\%, kegagalan kendaraan 11,11\% dan, buruknya kondisi jalan eksisting 22,22\%. Setelah menerapkan 3 strategi penangan yang meliputi mendidik pengguna jalan, meningkatkan strategi jalan yang lebih aman, dan meningkatkan keselamatan jalan dan spesifikasi teknis, angka kecelakaan menurun hingga 50\% (Sandhyavitri et al., 2017). Hasil penelitian tersebut juga didukung dengan penelitian yang sama menyebutkan bahwa manusia merupakan faktor penyebab kecelakaan dan fatalitas yang paling utama 66.88\%, Jalan 12.78\%, Lingkungan 11.33\%, dan Kendaraan 9.21\% (Djunaidi, 2017). Tipe pergerakan kendaraan yang paling banyak menyebabkan kecelakaan yaitu tabrakan depan-depan 24\% dan depan-samping 22\% (Herawati, 2019).

Sebuah penelitian di provinsi lampung dengan meninjau 93 ruas jalan menyebutkan penyebab kecelakaan adalah kecepatan yang tinggi pada titik rawan kecelakaan dengan rekomendasi penanganan penambahan kebutuhan fasilitas keselamatan seperti perlengkapan jalan (Oktopianto et al., 2021). Pada lokasi rawan kecelakaan Cikundul jalan raya puncak Jawa Barat merekomendasikan penanganan yang perlu dilakukan berupa pemasangan rambu-rambu lalulintas, pemasangan marka jalan, pemasangan pagar, memperbaiki kondisi geometrik jalan, dan meningkatkan visibilitas (Sudiatmono \& Santosa, 2010). Pada faktor penyebab kecelakaan dominan pengguna jalan penanganan dalam mengurangi tingkat kecelakaan lalu lintas pada daerah rawan kecelakaan direkomendasikan dengan pembuatan fasilitas jalan raya berupa rambu batasan kecepatan, rambu penunjuk arah (Sartika Nisumantri, 2018).

Informasi mengenai daerah rawan kecelakaan sangat dibutuhkan oleh masyarakat dan penegak hukum. Informasi tersebut dapat dijadikan bahan pertimbangan untuk pengawasan maupun tindakan antisipasi bagi kepolisian (Arumsari et al., 2016). Identifikasi ruas jalan dengan kecelakaan berisiko tinggi adalah langkah pertama untuk setiap proses manajemen keselamatan jalan yang berhasil (Ghadi \& Török, 2019). Tindakan yang dapat dilakukan untuk mengurangi kecelakaan pada lokasi titik rawan kecelakaan yaitu dengan membandingkan kondisi ruas jalan yang rawan kecelakaan dengan ruas jalan tingkat kecelakaan rendah, sehingga dapat diambil tindakan teknis (Khomeini \& Taufik, 2017). Analisis daerah rawan kecelakaan dapat dilakukan sebagai upaya untuk mengetahui penanganan yang tepat terhadap kecelakaan lalu lintas. Masalah 
kecelakaan lalu lintas menjadi suatu hal yang vital yang perlu dilakukan kajian terhadapnya, baik mengenai penyebab, akibat, dan penanganannya (Oktopianto \& Pangesty, 2021). Tujuan dari penelitian ini untuk mengidentifikasi lokasi rawan kecelakaan dan menganalisis penanganan daerah rawan kecelakaan Kabupaten Karanganyar.

\section{Metode Penelitian}

Lokasi penelitian ini di ruas jalan nasional Kabupaten Karanganyar. Penelitian ini menggunakan penelitian kuantitatif dengan mendapatkan data melalui data primer dan sekunder yang digunakan sebagai bahan analisis data. Tahapan yang dilakukan dalam penelitian ini adalah:

1. Studi literatur, yaitu untuk melakukan tinjauan terkait identifikasi lokasi rawan kecelakaan yang berupa titik rawan kecelakaan lalu lintas

2. Pengumpulan data, pengumpulan data meliputi data primer yang merupakan data yang langsung didapatkan di lapangan dan data sekunder yang merupakan data yang didapatkan dari sumber.

Data primer dan data sekunder dalam penelitian ini yaitu:

a. Data primer meliputi Survei inventarisasi jalan dilakukan dengan maksud untuk mengetahui kondisi ruas jalan di wilayah studi. Kondisi yang diamati adalah meliputi Panjang ruas, lebar, perkerasan jalan, tipe jalan, fasilitas dan perlengkapan jalan yang ada seperti rambu dan marka jalan. Survei Konflik Lalu Lintas, ini dimaksudkan untuk mengetahui pola pergerakan kendaraan yang menyebabkan kecelakaan lalu lintas.

b. Data sekunder yaitu berupa data dari Dinas Perhubungan Kabupaten Karanganyar yang terdiri dari data dibidang lalu lintas, yaitu data LHRT dan kapasitas ruas jalan meliputi jalan nasional. Data dibidang sarana dan prasarana, yaitu data perlengkapan jalan. Data kecelakaan dari kepolisian selama 6 Tahun terakhir (2016-2020) yang terjadi di Kabupaten Karanganayar.

3. Analisis data, yaitu meliputi analisis penentuan daerah rawan kecelakaan menggunakan metode EAN, dan Frekuensi Kecelakaan.

4. EAN dihitung dengan menjumlahkan kejadian kecelakaan pada setiap kilometer panjang jalan kemudian dikalikan dengan nilai bobot sesuai tingkat keparahan. Z-Score adalah bilangan "z" atau bilangan standar atau bilangan baku. Bilangan " $\mathrm{z}$ " dicari dari sampel yang berukuran $\mathrm{n}$, dengan data-data $\mathrm{X} 1, \mathrm{X} 2, \mathrm{X} 3, \ldots \ldots . \mathrm{Xn}$ dengan rata-rata $\mathrm{X}$ pada simpangan baku "S", sehingga dapat dibentuk data baru yaitu $\mathrm{z} 1, \mathrm{z} 2, \mathrm{z} 3, \ldots \ldots . . \mathrm{zn}$ dengan rata-rata 0 simpangan baku 1 . Dengan kata lain, nilai z dapat dikatakan seberapa standar deviasi jauh jarak nilai suatu data dengan nilai mean nya. Frekuensi kecelakaan sama dengan jumlah kecelakaan lalu lintas per satuan waktu atau per lokasi. Analisa yang digunakan dalam metode frekuensi adalah dengan membandingkan antara jumlah kejadian kecelakaan dengan rata-rata kecelakaan, jika jumlah kejadian kecelakaan lebih tinggi dari rata-ratanya maka ruas jalan tersebut dikatakan blacksite, sebaliknya jika jumlah kejadian kecelakaan pada suatu ruas tidak lebih tinggi dari rata-ratanya maka dikatakan bukan blacksite.

5. Analisis titik rawan kecelakaan menggunakan metode Cumulative Summary.

Cusum (Cummulative Summary) adalah suatu prosedur yang dapat digunakan untuk mengidentifikasi Black Spot. Grafik Cusum merupakan suatu prosedur statistik standar sebagai kontrol kualitas untuk mendeteksi perubahan dari nilai mean.

6. Penanganan Daerah Rawan Kecelakaan.

Penanganan daerah rawan kecelakaan atau daerah potensi kecelakaan lalu lintas merupakan analisis kecelakaan lalu lintas dalam skala mikro pada lokasi atau daerah dengan bobot tertinggi 
berdasarkan hasil identifikasi dan pemeringkatan daerah rawan kecelakaan. Adapun tahapannya antara lain :
a. Analisis kondisi lalu lintas
b. Analisis perilaku pengemudi
c. Analisis perilaku pejalan kaki
d. Analisis konflik lalu lintas
e. Inspeksi keselamatan jalan
f. Usulan penanganan daerah rawan kecelakaan atau daerah potensi kecelakaan.

\section{Hasil dan Pembahasan}

\subsection{Analisis Lokasi Rawan Kecelakaan}

Untuk mengetahui lokasi rawan kecelakaan yang terdapat di Kabupaten Karanganyar dilakukan analisis lokasi rawan kecelakaan menggunakan data kecelakaan dalam 5 tahun terakhir dari tahun 2016 sampai dengan tahun 2020. Data tersebut diperoleh dari Satlantas Polres Karanganyar. Hasil analisis lokasi rawan kecelakaan menggunakan metode EAN untuk dua ruas jalan nasional yang terdapat di Kabupaten Karanganyar dapat dilihat pada tabel 1.

Tabel 1. Hasil Analisis Lokasi Rawan Kecelakaan

\begin{tabular}{|c|c|c|c|c|c|c|}
\hline \multirow[t]{2}{*}{ Ruas Jalan Nasional } & \multicolumn{3}{|c|}{$\begin{array}{c}\text { Jumlah Keseluruhan } \\
2016-2020\end{array}$} & \multirow{2}{*}{$\begin{array}{l}\text { Total } \\
\text { AEK }\end{array}$} & \multirow[t]{2}{*}{ BKA } & \multirow[t]{2}{*}{ Keterangar } \\
\hline & MD & LB & LR & & & \\
\hline Jl. Palur - Batas Kab. Sragen & 41 & 2 & 349 & 1551 & 860,62 & Blacklink \\
\hline Jl. Batas Kota Surakarta - Palur & 0 & 0 & 1 & 3 & 860,62 & $\begin{array}{l}\text { Bukan } \\
\text { Blacklink }\end{array}$ \\
\hline Jumlah & & & & 1554 & & \\
\hline Rata-rata & & & & 777 & & \\
\hline BKA & & & & 860,624 & & \\
\hline
\end{tabular}

Berdasarkan table 1 diatas dari 2 ruas jalan nasional yang telah dianalisis menggunakan metode EAN, terdapat 1 ruas jalan yang masuk dalam kategori blacklink yaitu ruas jalan Palur - Batas kabupaten Sragen dengan nilai EAN sebesar 1551 yang berada diatas nilai batas kontrol atas yaitu 860,62. Selain menggunakan metode EAN analisis lokasi rawan kecelakaan jalan nasional juga menggunakan metode frekuensi dengan menggunakan total jumlah kecelakaan. Berikut adalah analisis yang telah dilakukan menggunakan frekuensi untuk jalan nasional yang terdapat di Kabupaten Karanganyar. Hasil analisis dapat dilihat pada tabel 2.

Tabel 2. Hasil Analisa Lokasi Rawan Kecelakaan Jalan Nasional Menggunakan Metode Frekuensi

\begin{tabular}{ccccccccc}
\hline & \multicolumn{9}{c}{ Jumlah Kejadian } & & $\mathbf{X}$ & $\overline{\mathbf{X}}$ & Keterangan \\
\cline { 2 - 9 } Ruas Jalan Nasional & $\mathbf{2 0 1 6}$ & $\mathbf{2 0 1 7}$ & $\mathbf{2 0 1 8}$ & $\mathbf{2 0 1 9}$ & $\begin{array}{c}\mathbf{2 0} \\
\mathbf{2 0}\end{array}$ & & & \\
\hline $\begin{array}{c}\text { Jl. Batas Kota } \\
\text { Surakarta-Palur }\end{array}$ & 1 & 0 & 0 & 0 & 0 & 1 & 163 & Bukan Blacklink \\
Jl. Palur-Batas Sragen & 58 & 67 & 65 & 78 & 57 & 325 & 163 & Blacklink \\
\hline Jumlah & & & & & & 326 & & \\
\hline
\end{tabular}

Keterangan: X: Nilai Frekuensi; $\bar{X}$ : Nilai Rata-Rata 
Berdasarkan table 2 dari dua ruas jalan yang telah dianalisis menggunakan metode frekuensi, terdapat satu ruas jalan yang termasuk dalam kategori blacklink yaitu ruas jalan Palur - Batas Kabupaten Sragen dengan nilai frekuensi sebesar 325. Ruas jalan tersebut dalam kategori blacklink dikarenakan nilai total frekuensi lebih besar dari nilai rata-rata sebesar 163. Selanjutnya untuk mengidentifikasi blacksite menggunakan metode Cussum. Hasil perhutungan Cussum dapat dilihat pada tabel 3.

Tabel 3. Hasil Analisa Blacksite Jalan Palur - Batas Kabupaten Sragen Menggunakan Metode Cussum

\begin{tabular}{cccccccc}
\hline STA & Tahun & Xi & W & So & Si & C & Keterangan \\
\hline \multirow{5}{*}{ Sta 2 - Sta 3 } & 2016 & 8 & 0,12 & 7,88 & 15,75 & & \\
& 2017 & 10 & 0,15 & 9,85 & 19,69 & & \\
& 2018 & 8 & 0,12 & 7,88 & 15,75 & 23,63 & BLACKSITE \\
& 2019 & 12 & 0,18 & 11,82 & 23,63 & & \\
& 2020 & 11 & 0,17 & 10,83 & 21,66 & & \\
Sta 6 - Sta 7 & 2016 & 11 & 0,17 & 10,83 & 21,66 & & \\
& 2017 & 14 & 0,22 & 13,78 & 27,57 & & \\
& 2018 & 17 & 0,26 & 16,74 & 33,48 & 33,48 & BLACKSITE \\
& 2019 & 15 & 0,23 & 14,77 & 29,54 & & \\
Sta 7 - Sta 8 & 2020 & 13 & 0,20 & 12,80 & 25,60 & & \\
& 2016 & 8 & 0,12 & 7,88 & 15,75 & & \\
& 2017 & 8 & 0,12 & 7,88 & 15,75 & & \\
& 2018 & 8 & 0,12 & 7,88 & 15,75 & 17,72 & BLACKSITE \\
& 2019 & 5 & 0,08 & 4,92 & 9,85 & & \\
\hline
\end{tabular}

Sumber : Hasil Analisis, 2021

Keterangan: $X_{1}$ : Jumlah kecelakaan tiap tahun; W: Nilai mean; So: Nilai Cussum Kecelakaan Untuk Tahun Pertama; S1: Nilai cussum kecelakaan; C: Cussum

Dari hasil analisis menggunakan metode Cussum terdapat $3 \mathrm{~km}$ yang termasuk dalam kategori blacksite yaitu Sta 2 - Sta 3, Sta 6 - Sta 7, Sta 7 - 8. Dari 3 Sta tersebut yang memiliki nilai Cussum tertinggi adalah Sta $6-7$. Kemudian Sta $6-7$ dibagi 10 segmen yang dianalisis untuk menentukan blackspot seperti pada tabel 4.

Tabel 4. Hasil Analisa Blackspot Jalan Palur - Batas Kabupaten Sragen Menggunakan Metode Cussum

\begin{tabular}{cccccccc}
\hline STA & Tahun & Xi & W & So & Si & C & Keterangan \\
\hline & 2016 & 3 & 0,06 & 2,94 & 5,88 & & \\
Sta 6+800 - & 2017 & 5 & 0,10 & 4,90 & 9,80 & & \\
Sta 6+900 & 2018 & 6 & 0,12 & 5,88 & 11,76 & 11,76 & BLACKSPOT \\
& 2019 & 4 & 0,08 & 3,92 & 7,84 & & \\
\hline \multirow{3}{*}{ Sta 6+500 - } & 2020 & 4 & 0,08 & 3,92 & 7,84 & & \\
Sta 6+600 & 2016 & 1 & 0,02 & 0,98 & 1,96 & & \\
& 2017 & 0 & 0,00 & 0,00 & 0,00 & & \multirow{2}{*}{ BLACKSPOT } \\
\cline { 2 - 5 } & 2018 & 1 & 0,02 & 0,98 & 1,96 & 5,88 & \\
\hline
\end{tabular}

Sumber : Hasil Analisis, 2021 
Keterangan: $X_{1}$ : Jumlah kecelakaan tiap tahun; W: Nilai mean; So: Nilai Cussum Kecelakaan Untuk Tahun Pertama; S1: Nilai cussum kecelakaan; C: Cussum

Dari hasil analisis menggunakan metode Cussum pada ruas jalan Palur - Karanganyar KM 6-7 diperoleh blackspot di STA 6+800 - 6+900 dan STA 6+500 - 6+600.

\subsection{Penanganan Daerah Rawan Kecelakaan}

Tahapan penanganan lokasi rawan kecelakaan menjelaskan tentang rekomendasi perbaikan pada lokasi titik rawan kecelakaan berdasarkan hasil analisis. Tahapan yang dilakukan adalah sebagai berikut.

\subsubsection{Profil Kecelakaan}

Berdasarkan analisis data yang telah dilakukan, ruas jalan yang menghubungkan Palur dengan Batas Kabupaten Sragen termasuk lokasi rawan kecelakaan dengan blackspot yang berada di KM 6-7 tepatnya di depan pabrik Delta. Dari tahun 2016 sampai dengan tahun 2020 telah terjadi 325 kecelakaan di sepanjang ruas jalan yang tersebar di beberapa titik. Karakteristik kecelakaan yang terjadi di sepanjang ruas jalan Palur - Batas Kabupaten Sragen dalam kurun waktu 2016 - 2020 dapat dilihat gambar pada gambar 1.

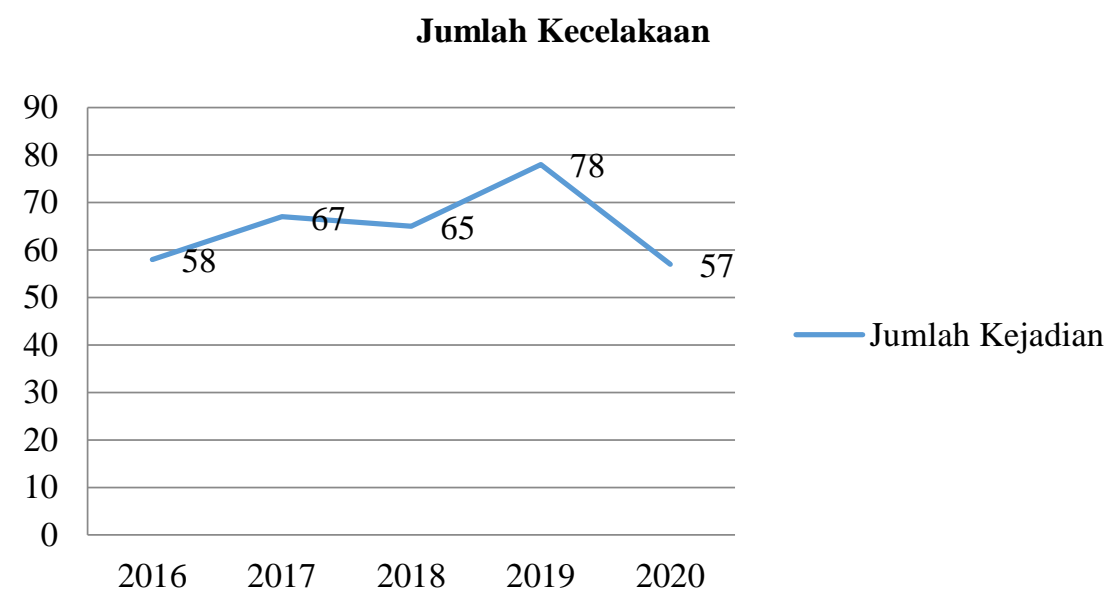

Gambar 1. Grafik Jumlah Kecelakaan Jalan Palur - Batas Kabupaten Sragen

Berdasarkan gambar dan grafik diatas, terjadi fluktuasi jumlah kecelakaan yang terjadi di ruas Jalan Palur - Batas Kabupaten Sragen, pada tahun 2016 terjadi 58 kecelakaan kemudian pada tahun 2017 mengalami peningkatan menjadi 67 kecelakaan, akan tetapi pada tahun 2018 mengalami penurunan menjadi 65 kecelakaan. Namun pada tahun 2019 kembali mengalami kenaikan menjadi 78 kecelakaan dan pada tahun 2020 mengalami penurunan menjadi 57 kecelakaan.

\subsubsection{Volume Lalu Lintas}

Survei volume lalu lintas merupakan survei yang dilakukan untuk memperoleh jumlah kendaraan yang melewati suatu jalur dari segmen jalan selama periode waktu yang tertentu. Survei volume lalu lintas dilakukan di ruas jalan Palur - Batas Kabupaten Sragen KM 6,9 pada jam rawan kecelakaan yaitu pada pukul $08.00-09.00$ WIB.

Berdasarkan grafik diatas, diketahui bahwa ruas jalan Palur - Batas Kabupaten Sragen untuk arah menuju Palur volume tertinggi terdapat pada pukul 08.00 - 08.15 WIB sebanyak 594 
kendaraan/jam sedangkan untuk arah menuju Batas Kabupaten Sragen volume tertinggi pukul 08.45-09.00 WIB sebanyak 468 kendaraan/jam. Hal tersebut terjadi karena masyarakat melakukan aktivitas seperti pergi bekerja baik itu ke pasar, kantor dan pabrik yang berada di ruas jalan Palur Batas Kabupaten Sragen. Dari hasil analisis volume lalu lintas selanjutnya dilakukan perhitungan kapasitas jalan untuk mengetahui tingkat pelayanan ruas jalan Palur - Batas Kabupaten Sragen disajikan pada tabel 5 .

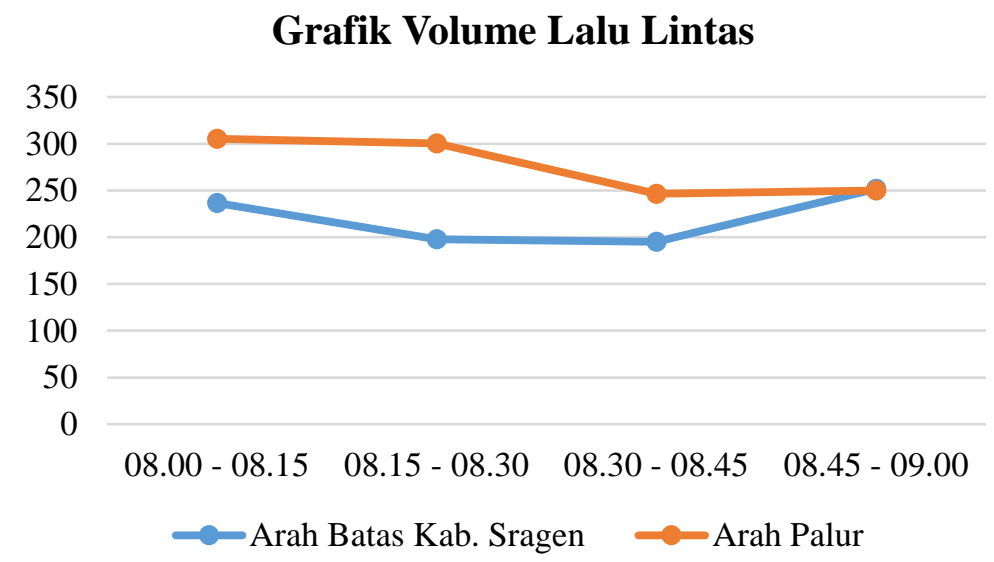

Gambar 2. Grafik Volume Lalu Lintas Jalan Palur - Batas Kabupaten Sragen

Tabel 5. Kapasitas Jalan Palur - Batas Kabupaten Sragen

\begin{tabular}{|c|c|c|}
\hline Faktor Penyesuaian & Hasil Survei & Koefisien \\
\hline Co / Kapasitas Dasar & Empat Lajur terbagi & 1650 \\
\hline Fcw & 7,5 meter & 1,08 \\
\hline FCsp & $50-50$ & 1 \\
\hline FCsf & VL (1) & 1,03 \\
\hline FCcs & $0,5-1,0$ & 0,94 \\
\hline \multicolumn{2}{|c|}{$\mathrm{C}(\mathrm{smp} / \mathrm{jam})$} & 1725,33 \\
\hline
\end{tabular}

Sumber : Hasil Analisis, 2021

Dari analisis perhitungan kapasitas ruas jalan Palur - Batas Kabupaten Sragen, diketahui bahwa kapasitas ruas Jalan Palur-Batas Kabupaten Sragen yaitu 1725,33 smp/jam. Dari hasil perhitungan kapasitas jalan selanjutnya digunakan untuk mengetahui tingkat pelayanan ruas jalan Palur-Batas Kabupaten Sragen.

Dari hasil analisis perhitungan, ruas Jalan Palur-Batas Kabupaten Sragen memiliki V/C ratio sebesar 0,51 untuk arah Batas Kabupaten Sragen dan untuk arah Palur V/C ratio sebesar 0,63 dimana tingkat pelayanan pada jalan Palur - Batas Kabupaten Sragen pengemudi memiliki arus stabil dengan kecepatan lebih dari $60 \mathrm{~km} / \mathrm{jam}$. Ruas Jalan Palur - Batas Kabupaten Sragen merupakan jalan utama yang cukup ramai yang menghubungkan jalan Palur (Karanganyar) menuju Kabupaten Sragen, dimana mayoritas pengguna jalan yang melewati ruas jalan ini adalah pekerja pabrik dan kantor yang berusaha mencapai tujuan mereka masing - masing dalam waktu singkat 
Tabel 6. Tingkat Pelayanan Ruas Jalan Palur-Batas Kabupaten Sragen

\begin{tabular}{|c|c|c|c|c|c|}
\hline Arah & $\begin{array}{c}\text { Arus } \\
\text { Total } \\
\text { (V) } \\
\end{array}$ & $\begin{array}{c}\text { Kapasitas } \\
\text { (C) }\end{array}$ & $\mathrm{V} / \mathrm{C}$ & $\begin{array}{c}\text { Tingkat } \\
\text { Pelayanan }\end{array}$ & Karakteristik Lalu Lintas \\
\hline $\begin{array}{c}\text { Batas } \\
\text { Kabupaten } \\
\text { Sragen }\end{array}$ & 881,1 & 1725,33 & 0,51 & $\mathrm{C}$ & $\begin{array}{l}\text { - Arah stabil tetapi pergerakan kendaraan } \\
\text { dikendalikan oleh volume lalu lintas yang } \\
\text { lebih tinggi dengan kecepatan sekurang - } \\
\text { kurangnya } 60 \mathrm{~km} / \text { jam. } \\
\text { Kecepatan lalu lintas sedang karena } \\
\text { hambatan internal lalu lintas meningkat } \\
\text { Pengemudi memiliki keterbatasan untuk } \\
\text { memilih kecepatan, pindah jalur untuk } \\
\text { mendahului }\end{array}$ \\
\hline Palur & 1102 & 1725,33 & 0,63 & $\mathrm{C}$ & $\begin{array}{l}\text { - Arah stabil tetapi pergerakan kendaraan } \\
\text { dikendalikan oleh volume lalu lintas yang } \\
\text { lebih tinggi dengan kecepatan sekurang - } \\
\text { kurangnya } 60 \mathrm{~km} / \text { jam. } \\
\text { Kecepatan lalu lintas sedang karena } \\
\text { hambatan internal lalu lintas meningkat } \\
\text { - Pengemudi memiliki keterbatasan untuk } \\
\text { memilih kecepatan, pindah jalur untuk } \\
\text { mendahului }\end{array}$ \\
\hline
\end{tabular}

Sumber: Hasil Analisi. 2021

\subsubsection{Kecepatan Kendaraan}

Tabel 7. Kecepatan Kendaraan Arah Palur

\begin{tabular}{ccccc}
\hline \multirow{2}{*}{ Jenis Kendaraan } & \multicolumn{4}{c}{ Arah Palur $(\mathbf{k m} / \mathbf{j a m})$} \\
\cline { 2 - 5 } & Kec. Minimal & Kec. Maksimal & Kec. Rata - rata & Persentil 85 \\
\hline MC & 27 & 79 & 48,79 & 58,1 \\
LV & 25 & 73 & 51,29 & 64,7 \\
HV & 24 & 71 & 40,31 & 49,8 \\
\hline
\end{tabular}

Sumber : Hasil Analisis, 2021

Tabel 8. Kecepatan Kendaraan Arah Karanganyar

\begin{tabular}{ccccc}
\hline \multirow{2}{*}{ Jenis Kendaraan } & \multicolumn{4}{c}{ Arah Karanganyar (km/jam) } \\
\cline { 2 - 5 } & Kec. Minimal & Kec. Maksimal & Kec.Rata - rata & Persentil 85 \\
\hline MC & 33 & 87 & 55,81 & 70 \\
LV & 37 & 76 & 55,45 & 65 \\
HV & 20 & 51 & 35,16 & 41,7 \\
\hline
\end{tabular}

Sumber : Hasil Analisis, 2021

Berdasarkan tabel 7 dan tabel 8 hasil survei kecepatan kendaraan baik arah Palur maupun sebaliknya arah Karanganyar bahwa kecepatan kendaraan yang diperoleh tidak melebihi batas kecepatan sesuai dengan PM 111 Tahun 2015 yaitu sebesar 80 km/jam.

\subsubsection{Perilaku Pengemudi}

Survei Perilaku Pengemudi merupakan survei yang dilakukan untuk menganalisa pola perilaku pengemudi kendaraan bermotor. Selain faktor jalan dan faktor kendaraan, faktor banyak manusia merupakan faktor yang paling mengakibatkan kecelakaan lalu lintas. Survei ini dilakukan pada hari 
Senin, 1 Maret 2021 pada pukul 08.00 - 09.00 WIB. Berikut adalah beberapa survei perilaku pengemudi yang telah dilakukan. Oleh karena itu, perlu dilakukan survei mengenai perilaku pengemudi yang melewati ruas Jalan Palur - Batas Kab. Sragen. Survei penggunaaan dilakukan di lokasi rawan kecelakaan yaitu ruas Jalan Palur - Batas Kab.Sragen KM 6,9.

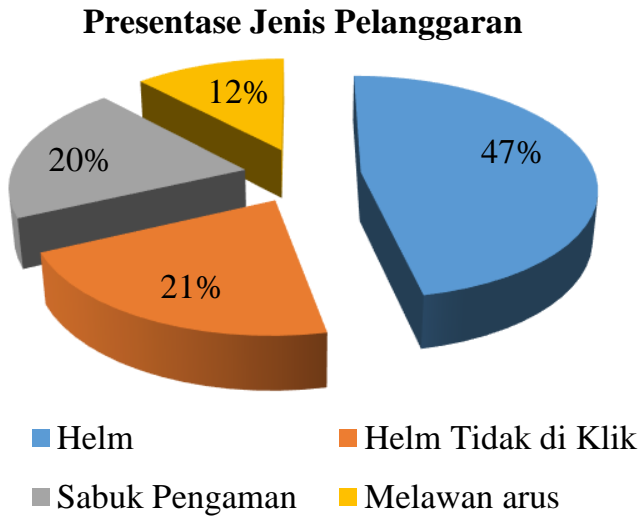

\section{Gambar 3. Persentase Jenis Pelanggaran Pengemudi}

Berdasarkan gambar 3, dari survei perilaku pengemudi yang telah dilakukan terdapat 4 jenis perilaku pelanggaran pengemudi yang melintas di ruas Jalan Palur - Batas Kabupaten Sragen tepatnya di KM 6,9. Dapat diketahui bahwa pelanggaran pengemudi dengan persentase tertinggi adalah pelanggaran tidak menggunakan helm . Hal ini disebabkan karena pengendara sepeda motor beranggapan bahwa jika jarak terlalu dekat untuk bepergian menggunakan sepeda motor tidak perlu menggunakan helm.

\subsubsection{Konflik Lalu Lintas}

Konflik lalu lintas dapat diamati jika ada dua pengguna jalan atau lebih mendekati satu sama lain pada ruang dan waktu yang sama memliki risiko terjadinya tabrakan jika pengguna jalan tersebut tidak berubah. Ada beberapa konflik yang terjadi di Jalan Palur - Batas Kabupaten Sragen yaitu gerakan bergabung (merging), gerakan memisah (diverging) dan bersilangan (crossing). Teknik yang dilakukan adalah menghitung jumlah konflik yang terjadi melalui pengamatan langsung oleh dua surveyor ditempatkan pada titik. Survei dilakukan pada hari Senin, 1 Maret 2021 pada pukul $08.00-09.00 \mathrm{WIB}$.

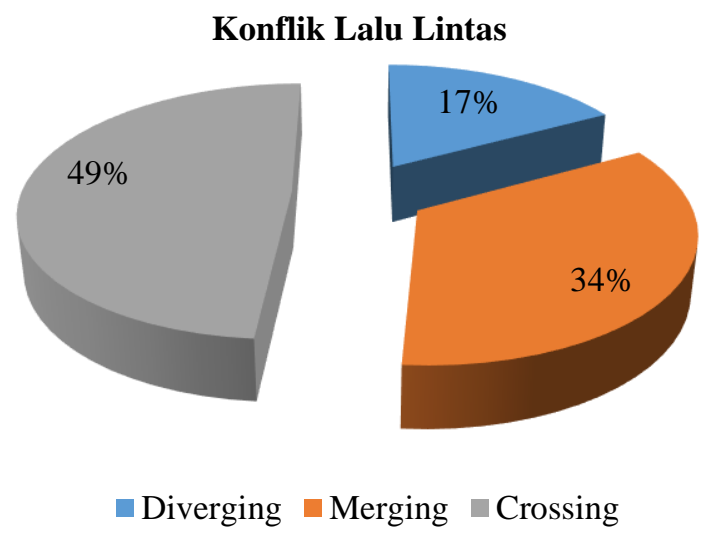

Gambar 4. Persentase Konflik Lalin Jalan Nasional 
Berdasarkan hasil survei konflik lalu lintas, konflik yang paling banyak terjadi adalah crossing sebanyak 57 kejadian, hal ini disebabkan karena banyak pengguna jalan yang melewati bukaan median yang berfungsi akses menuju jalan minor. Jenis konflik yang memiliki jumlah tertinggi kedua yaitu merging sebanyak 40 kejadian, hal ini disebabkan karena banyak kendaraan yang berputar balik arah sehingga membuat kendaraan dari belakang yang berkecepatan tinggi hampir tidak bisa mengendalikan kecepatan yang membuat konflik.

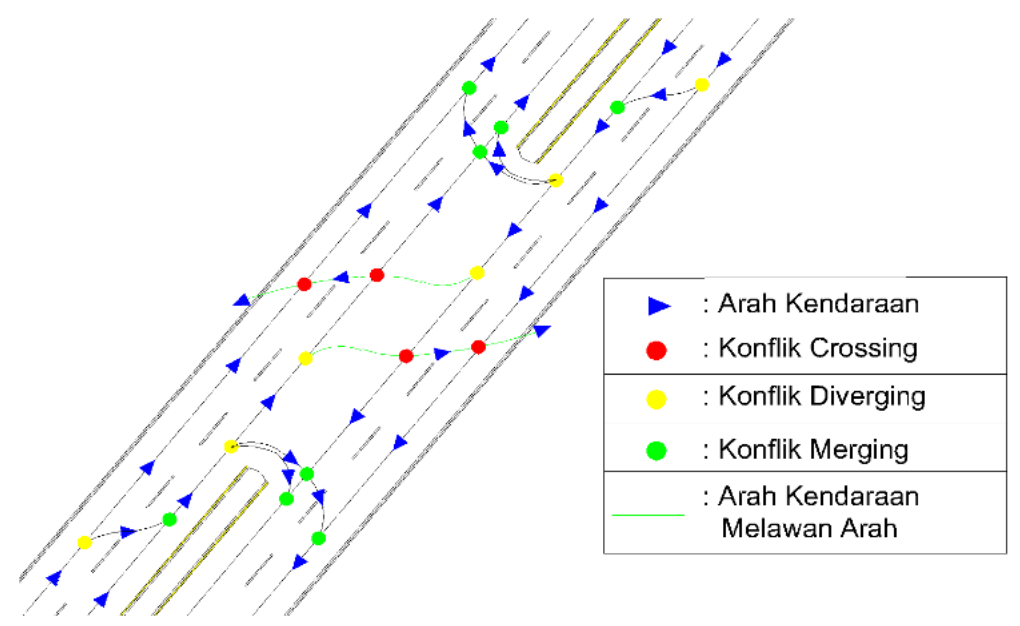

Gambar 5. Konflik Lalu Lintas Jalan Nasional

\subsubsection{Inspeksi Keselamatan Jalan}

Berikut merupakan hasil inspeksi keselamatan jalan yang dilakukan 200 meter sebelum dan sesudah blackspot. Survei ini dilakukan di ruas Jalan Palur - Batas Kabupaten Sragen pada hari Senin, 01 Maret 2021 pada pukul 08.00 - 09.00 WIB.

Tabel 9. Hasil Inspeksi Keselamatan Jalan Nasional

\begin{tabular}{|c|c|c|}
\hline No & $\begin{array}{c}\text { Nama Jenis } \\
\text { Perlengkapan Jalan }\end{array}$ & Keterangan \\
\hline 1 & Marka & $\begin{array}{l}\text { Marka yang berada di sepanjang jalan Palur - Batas Kabupaten Sragen } \\
\text { sudah dalam kondisi warna cat mulai memudar. }\end{array}$ \\
\hline 2 & Median & $\begin{array}{l}\text { Terdapat median di sepanjang ruas jalan Palur - Batas Kabupaten Sragen } \\
\text { dalam kondisi baik. }\end{array}$ \\
\hline 3 & Rambu & $\begin{array}{l}\text { Terdapat rambu U- Turn di ruas jalan Palur - Batas Kabupaten Sragen } \\
\text { dalam kondisi baik. }\end{array}$ \\
\hline 4 & $\begin{array}{l}\text { Penerangan Jalan } \\
\text { Umum }\end{array}$ & $\begin{array}{l}\text { Terdapat lampu penerangan jalan di sepanjang ruas jalan Palur - Batas } \\
\text { Kabupaten Sragen dalam kondisi baik. }\end{array}$ \\
\hline 5 & Geometrik Jalan & $\begin{array}{l}\text { Kondisi Jalan yang berada di jalan Palur - Batas Kabupaten Sragen } \\
\text { dalam kondisi berlubang dan rusak. }\end{array}$ \\
\hline 6 & Bahu Jalan & $\begin{array}{l}\text { Bahu yang ada di jalan Palur - Batas Kabupaten Sragen dalam kondisi } \\
\text { berlubang dan terdapat genangan air. }\end{array}$ \\
\hline
\end{tabular}

\subsubsection{Analisis Penyebab Kecelakaan}

Berdasarkan analisis data diatas, terdapat beberapa permasalahan yang ada di ruas jalan Palur Batas Sragen.

a. Ruas jalan Palur - Batas Kabupaten Sragen memiliki tingkat pelayanan C dimana pengemudi masih dapat memilih kecepatan yang diinginkan sehingga dapat berdampak pada kecepatan lalu 
lintas yang ada. Berdasarkan hasil survei, untuk kecepatan sesaat arah dari Palur menuju Sragen yakni $70 \mathrm{~km} / \mathrm{jam}$ untuk sepeda motor, $65 \mathrm{~km} / \mathrm{jam}$ untuk kendaraan ringan, dan $57 \mathrm{~km} / \mathrm{jam}$ untuk kendaraan berat. Sementara kecepatan sesaat kendaraan yang melintas dari arah Sragen menuju Palur, sepeda motor memiliki kecepatan sebesar $58 \mathrm{~km} / \mathrm{jam}$, kendaraan ringan sebesar 65 $\mathrm{km} / \mathrm{jam}$, dan kendaraan berat sebesar $49 \mathrm{~km} / \mathrm{jam}$.

b. Bila dari arah Palur menuju Sragen, terdapat persimpangan sebelum titik lokasi rawan kecelakaan yang terletak pada bukaan sekitar PT. Delta Merlin Dunia. Sebelum melintasi persimpangan tersebut di kondisi eksisting belum adanya perambuan peringatan adanya persimpangan dan hati-hati. Sementara cukup banyak juga pengendara yang masuk dari persimpangan tersebut menuju jalan nasional, melakukan gerakan membelok ke kiri dan langsung mengambil lajur kanan untuk melakukan putar arah di bukaan median, disisi lain bukaan median tersebut cukup banyak kendaraan yang melakukaan putar arah dari kedua arah jalur.

c. Tipe kecelakaan paling banyak yang terjadi adalah tipe tabrak depan - samping dengan kendaraan terlibat yang mendominasi ialah sepeda motor. Hal ini disebabkan karena pengemudi kendaraan bermotor tidak bisa menguasai laju kendaran saat menjumpai kendaraan yang hendak berputar arah. Hal ini bisa diantispasi bila pengendara menerapkan jarak aman antar kendaraan.

d. Waktu kecelakaan paling sering terjadi pada pukul 06.00-12.00 WIB. Hal ini terjadi karena pada jam tersebut kondisi lalu lintas ramai yang menyebabkan kewaspadaan pengguna jalan berkurang. Selain itu karena adanya aktifitas kegiatan pabrik dan pegawai pabrik di sekitar lokasi rawan kecelakaan.

e. Kondisi geometrik jalan di lokasi survei berupa jalan lurus yang landai, sehingga pengemudi dengan mudah untuk melaju dengan kecepatan yang tinggi.

f. Masih banyak dijumpai pelanggaran yang dilakukan oleh pengendara kendaraan kuhusnya pengendara yang melakukan putar balik dan menyeberang.

\subsubsection{Penanganan Daerah Rawan Kecelakaan}

Adapun rekomendasi penanganan jalur palur - batas sragen dapat dilihat pada tabel 10 di bawah ini,

\section{Tabel 10. Rekomendasi Penanganan Jalan Palur - Batas Sragen}

\begin{tabular}{|c|c|c|}
\hline No & Permasalahan & Rekomendasi \\
\hline 1 & $\begin{array}{l}\text { Tidak terdapat pembatasan } \\
\text { kecepatan untuk kendaraan } \\
\text { yang melintas. }\end{array}$ & $\begin{array}{l}\text { Pengadaan rambu batas kecepatan : Rambu ditempatkan di } \\
\text { sebelah kiri masing-masing lajur, ukuran daun rambu sedang, } \\
\text { inggi rambu } 1,75 \mathrm{~m} \text { dari permukaan tanah, jarak penempatan } \\
\text { rambu minimal } 0,6 \mathrm{~m} \text { dari bagian tepi paling luar bahu jalan. }\end{array}$ \\
\hline 2 & $\begin{array}{l}\text { Kurangnya rambu-rambu } \\
\text { lalu lintas yang menjelaskan } \\
\text { kondisi jalan eksisting. }\end{array}$ & $\begin{array}{l}\text { Pengadaan rambu peringatan persimpangan : Rambu } \\
\text { ditempatkan di sebelah kiri jalur arah Sragen, ukuran daun } \\
\text { rambu sedang, tinggi rambu } 1,75 \mathrm{~m} \text { dari permukaan tanah, jarak } \\
\text { penempatan minimal } 80 \mathrm{~m} \text { dari simpang, jarak penempatan } \\
\text { rambu minimal } 0,6 \mathrm{~m} \text { dari bagian tepi paling luar bahu jalan. }\end{array}$ \\
\hline & & $\begin{array}{l}\text { Pengadaan rambu petunjuk lokasi putar balik untuk dari jalur } \\
\text { dari arah Palur -menuju Sragen: Rambu ditempatkan di sebelah } \\
\text { kanan jalur arah Sragen, rambu dipasang pada pemisah jalan } \\
\text { (median) ditempatkan dengan jarak } 0,30 \mathrm{~m} \text { dari bagian paling } \\
\text { luar dari pemisah jalan, ukuran daun rambu sedang, tinggi } \\
\text { rambu } 2 \text { m dari permukaan tanah. }\end{array}$ \\
\hline 3 & $\begin{array}{l}\text { Tipe tabrakan yang terjadi } \\
\text { didominasi tabrak depan- } \\
\text { samping }\end{array}$ & Pengadaan rambu peringatan daerah rawan kecelakaan. \\
\hline
\end{tabular}




\section{Lanjuta Tabel 10. Rekomendasi Penanganan Jalan Palur - Batas Sragen}

\begin{tabular}{|c|c|c|}
\hline & & $\begin{array}{l}\text { Pengadaan perlengkapan jalan lampu apil satu warna (kuning): } \\
\text { Rambu ditempatkan di sebelah kiri masing-masing lajur, } \\
\text { penempatan berada sebelum bukaan median, jarak penempatan } \\
\text { rambu minimal } 0,6 \mathrm{~m} \text { dari bagian tepi paling luar bahu jalan, } \\
\text { tinggi penempatan armatur paling rendah } 5 \mathrm{~m} \text { diukur dari } \\
\text { permukaan ruang manfaat jalan tertinggi sampai dengan sisi } \\
\text { armatur bagian bawah (untuk armatur yang ditempatkan diatas } \\
\text { ruang manfaat jalan), posisi armatur diputer ke kanan atau ke } \\
\text { kiri paling banyak } 5 \text { derajat menghadap permukaan jalan dari } \\
\text { posisi tegak lurus sumbu jalan sesuai dengan arah lalu lintas. }\end{array}$ \\
\hline 4. & Kondisi jalan yang lurus & Pengadaan rambu hati-hati. \\
\hline 5. & $\begin{array}{l}\text { Banyaknya pengemudi yang } \\
\text { melanggar }\end{array}$ & $\begin{array}{l}\text { Melakukan sosialisasi keselamatan kepada masyararakat } \\
\text { setempat. }\end{array}$ \\
\hline 6. & Perbaikan marka & $\begin{array}{l}\text { Perbaikan ukuran marka putus putus: ukuran lebar marka } 0,12 \\
\text { m, panjang marka } 8 \mathrm{~m} \text {, jarak antar garis putus-putus } 5 \mathrm{~m}\end{array}$ \\
\hline 7. & $\begin{array}{l}\text { Tidak rambu simpang } \\
\text { prioritas yang terdapat di } \\
\text { jalan minor dekat SPBU } \\
\text { Dagen, yang mengakibatkan } \\
\text { paengguna jalan dari arah } \\
\text { minor tidak memberikan } \\
\text { prioritas pengguna jalan } \\
\text { yang berada pada jalan } \\
\text { utama. }\end{array}$ & $\begin{array}{l}\text { Penambahan rambu: a). daun rambu : panjang sisi } 75 \mathrm{~cm} \text {, garis } \\
\text { tepi luar } 1,9 \mathrm{~cm} \text {, panjang sisi segitiga dalam } 12,5 \mathrm{~cm} \text {; b). tinggi } \\
\text { tiang rambu tunggal : } 2 \text { meter; c). Penempatan rambu di jalan } \\
\text { minor; d. jarak antara penempatan rambu dengam badan jalan : } \\
0,6 \text { meter ; e. sudut pandang arah datangnya kendaraan. }\end{array}$ \\
\hline
\end{tabular}

Sumber : Hasil Analisis: 2021

\section{Kesimpulan}

Dari hasil analisis pada ruas jalan Palur - Batas Kabupaten Sragen (Jalan Nasional) lokasi rawan kecelakaan (Black Site) terletak pada ruas jalan Palur - Karanganyar KM 6-7 dengan titik rawan kecelakaan (Black Spot) di STA 6+800 - 6+900 dan STA 6+500 - 6+600. Rekomendasi penanganan daerah rawan kecelakaan yang di usulkan antara lain pengadaan rambu batas kecepatan, rambu peringatan persimpangan, rambu petunjuk putar balik, rambu peringatan DRK, rambu hati-hati, pengadaan APILL dengan satu warna (kuning), perbaikan marka dan sosialisasi terhadap masyarakat. Identifikasi daerah rawan kecelakaan perlu dilakukan secara berkala sebagai kontrol lokasi yang berpotensi menyebabkan kecelakaan. Rekomendasi penanganan pada daerah rawan kecelakaan yang diusulkan harus diterapkan dan dikoordinasikan dengan instansi terkait guna mengurangi atau menghilangkan daerah rawan kecelakaan.

\section{Daftar Pustaka}

Arumsari, N., Nugraha, A., \& Awaluddin, M. (2016). Pemodelan Daerah Rawan Kecelakaan Dengan Menggunakan Cluster Analysis (Studi Kasus: Kabupaten Boyolali). Jurnal Geodesi Undip.

Carina, F. (2014). Rawan Kecelakaan Lalu Lintas Di Kota Lubuklinggau. 24-31.

Djunaidi, A. (2017). Strategi Penanganan Titik Rawan Kecelakaan Ruas Jalan Sp. Penyandingan Pematang Panggang Jalur Lintas Timur Sumatera Selatan. Jurnal Tekno Global, 6(1). 
Ghadi, M., \& Török, Á. (2019). A comparative analysis of black spot identification methods and road accident segmentation methods. Accident Analysis and Prevention. https://doi.org/10.1016/j.aap.2019.03.002

Gregoriades, A., \& Mouskos, K. C. (2013). Black spots identification through a Bayesian Networks quantification of accident risk index. Transportation Research Part C: Emerging Technologies. https://doi.org/10.1016/j.trc.2012.12.008

Herawati, H. (2019). Karakteristik Dan Penyebab Kecelakaan Lalu Lintas Di Indonesia Tahun 2012. Warta Penelitian Perhubungan. https://doi.org/10.25104/warlit.v26i3.875

Isa Al Qurni. (2016). Analisis Daerah Rawan Kecelakaan Lalu Lintas (Studi Kasus Jalan Nasional Arteri Primer Dan Arteri Sekunder Kabupaten Kendal). Jurnal Geografi : Media Informasi Pengembangan Dan Profesi Kegeografian. https://doi.org/10.15294/jg.v13i1.7989

Kepolisian Kabupaten Karanganyar. (2020). Laporan Data Kecelakaan Kabupaten Karanganyar.

Khomeini, M., \& Taufik, S. (2017). Analisis Penanganan Lokasi Rawan Kecelakaan Lalu Lintas Di Kota Palangka Raya. Jurnal Teknologi Berkelanjutan (Sustainable Technology Journal).

Lestari, U. S. (2018). Analisis Penanganan Daerah Rawan Kecelakaan Di Di Ruas Jalan Ahmad Yani Kabupaten Tapin. Prosiding Simposium Forum Studi Transportasi Antar Perguruan Tinggi Ke-21, 19-20.

Oktopianto, Y., \& Pangesty, S. (2021). Analisis Daerah Lokasi Rawan Kecelakaan Jalan Tol Tangerang-Merak. Jurnal Keselamatan Transportasi Jalan (Indonesian Journal of Road Safety), 8(1), 26-37. https://doi.org/10.46447/ktj.v8i1.301

Oktopianto, Y., Shofiah, S., Rokhman, F. A., \& Pangestu, K. (2021). Analisis Daerah Rawan Kecelakaan ( Black Site ) Dan Titik Rawan Kecelakaan ( Black Spot ) Provinsi Lampung. Borneo Engineering: Jurnal Teknik Sipil, 5(1), 40-51. https://doi.org/10.35334/be.v5i1.1777

Sandhyavitri, A., Zamri, Wiyono, S., \& Subiantoro. (2017). Three Strategies Reducing Accident Rates at Black Spots and Black Sites Road in Riau Province, Indonesia. Transportation Research Procedia. https://doi.org/10.1016/j.trpro.2017.05.415

Sartika Nisumantri. (2018). Penentuan Daerah Rawan Kecelakaan Bagi Pengguna Jalan Pada Ruas Jalan Kol. H. Burlian Palembang. Tekno Global, 7(1), 28-38.

Sudiatmono, D. P., \& Santosa, W. (2010). Upaya Penanganan Lokasi Rawan Kecelakaan Ruas Jembatan Cikundul Jalan Raya Puncak Jawa Barat. Jurnal Transportasi, 10(3), 235-244. 
